\title{
Regulating Gene Expression in the Drosophila Germ Line
}

\author{
P. Rangan, M. DeGennaro, And R. Lehmann \\ HHMI and Kimmel Center for Biology and Medicine of the Skirball Institute, \\ Department of Cell Biology, New York University School of Medicine, New York, New York 10016
}

\begin{abstract}
Germ cells are the ultimate stem cells because they have the potential to give rise to a new organism. Specified during early embryogenesis in most species, germ cells evade somatic differentiation by using mechanisms such as transcriptional silencing and translational control (Seydoux and Braun 2006; Cinalli et al. 2008). To identify germ-line targets of translational regulation and to understand their mechanism of regulation, we used publicly available databases to identify RNAs localized to germ plasm. Using a transgenic reporter assay, we find that these germ-line RNAs are both spatially and temporally regulated during both oogenesis and embryogenesis by their $3^{\prime}$-untranslated regions (3'UTRs) (Rangan et al. 2008). We find that many RNAs that are spatially and temporally regulated in the early embryo are also translationally regulated during oogenesis. However, RNAs that are similarly regulated during oogenesis are no longer coregulated during embryogenesis, demonstrating that cis-acting sequences within a single RNA are used differentially during the life cycle of the germ line. Our study emphasizes a multifaceted role of translational regulation in germ cells. Many aspects of cellular behavior are shared between germ cells and other stem cells; thus, analysis of the translational regulatory networks controlling translation during the germline life cycle may reveal important general features of RNA regulation in stem cells.
\end{abstract}

Germ cells allow for the continuity of life in all sexually reproducing organisms by providing a link among generations and creating genetic diversity. In most organisms studied, germ cells are first to form and are set aside from somatic cells during early embryogenesis (Hayashi et al. 2007; Strome and Lehmann 2007; Cinalli et al. 2008). There are two main modes of specifying germ cells. First, as in Drosophila, germ cells arise from a maternally deposited cytoplasm called germ plasm that contains specialized RNA-protein particles, referred to as germ granules, $\mathrm{P}$ granules, or polar granules (Seydoux and Braun 2006). Second, in particular in mammals, germ cells are formed at the interface between the embryo and the extraembryonic tissue as the result of an inductive event requiring bone morphogenetic proteins 4 and 8 (BMP4/8) signaling (Hayashi et al. 2007). In mammals, primordial germ cells have the potential to differentiate into all germ layers and resemble pluripotent embryonic stem cells (Surani et al. 2007). Thus, understanding the mechanisms that primordial germ cells use to avoid somatic differentiation may provide more general insight into the control of pluripotency.

Although germ cells are specified by distinct mechanisms in different organisms, they share several common characteristics. One common characteristic is that in contrast to other tissues that develop in the early embryo, no conserved master transcriptional regulator has yet been identified for germ cells (Cinalli et al. 2008). Instead, one of the hallmarks of early germ cells is the fact that they are transcriptionally silent (Hayashi et al. 2007; Strome and Lehmann 2007; Cinalli et al. 2008; Nakamura and Seydoux 2008). This is achieved by direct repression of the function of RNA polymerase II (RNA Pol II), as was shown in Caenorhabditis elegans and in Drosophila, where the PIE-1 and Pgc proteins, respectively, interfere with phosphorylation and activation of the carboxy-terminal tail of RNA Pol II (Seydoux et al. 1996; Martinho et al.
2004; Hanyu-Nakamura et al. 2008; Nakamura and Seydoux 2008). In mouse, transcriptional repression in germ cells is chromatin mediated and requires Blimp1, a SET/PR domain and zinc-finger-containing protein (Ohinata et al. 2005; Vincent et al. 2005; Ancelin et al. 2006). Irrespective of the specific mechanism used, the outcome of this repression is that somatic differentiation programs are repressed in germ cells, allowing germ cells to develop. Mutations in any of these transcriptional regulators cause loss of germ cell specification or germ cell death (Nakamura et al. 1996; Seydoux et al. 1996; Martinho et al. 2004). Transcriptional repression is, however, not sufficient for germ cell specification because ectopic expression of these repressors independent of other factors that promote germ cell development does not lead to ectopic germ cell formation (Cinalli et al. 2008).

Another common characteristic of germ cells is the role that RNA regulators have in germ cell biology. RNA regulators are present throughout germ-line development and have important roles in both germ-line specification and maintenance (Seydoux and Braun 2006; Cinalli et al. 2008). In fact, two of these conserved RNA regulators, the RNA helicase Vasa and the translational repressor Nanos, are universal germ cell markers (Seydoux and Braun 2006). Functional analysis of mutations in RNA regulators suggests that they fulfill essential roles during germ-line development by preventing early differentiation of germ cells into gametes or preventing somatic dedifferentiation, such as in the case of nanos (Forbes and Lehmann 1998; Subramaniam and Seydoux 1999; Gilboa and Lehmann 2004; Hayashi et al. 2004; Wang and Lin 2004; Sato et al. 2007). These RNA regulators are thought to work by specifying the timing and spatial parameters of expression of target genes. Although several of the RNA regulators have been characterized and are known to affect all aspects of germ-line biology, little is known about the specific RNA targets and their regulation. 
In this study, we have identified targets of germ-line RNA regulators by compiling a list of RNAs localized to the germ plasm in the early embryo. We demonstrate that 3'UTRs of these germ-line RNAs are sufficient to localize RNAs to germ plasm by making reporter constructs. We investigated the translational state of these reporter constructs in the embryo and during oogenesis. Although all of the RNAs involved in this study show similar localization to the germ plasm, they are translated at different times in the germ line, showing that $3^{\prime}$ UTRs encode not only spatial information but also temporal information for translation. Moreover, when the expression pattern of RNAs in the embryo was compared to the pattern during oogenesis, we observed that RNAs that were similarly regulated in embryos are not necessarily regulated in similar pattern during oogenesis, suggesting that the information encoded by $3^{\prime}$ UTRs is dynamic and differentially used during the germ-line life cycle.

\section{RESULTS}

\section{Identification of Germ-line RNA}

To identify translational targets of conserved RNA regulators, we focused on RNAs present in the germ line throughout its life cycle. We used published reports to assemble a list of germ-cell-specific RNAs (Table 1) (Lecuyer et al. 2007; Tomancak et al. 2007). We focused on RNAs with an expression pattern similar to that previously described for nanos, germ-cell-less ( $\mathrm{gcl}$ ), and polar granule component (pgc) (Wang and Lehmann 1991; Jongens et al. 1992; Nakamura et al. 1996). These RNAs are synthesized during oogenesis and become localized to the germ plasm at the posterior pole of the oocyte at the end of oogenesis. Within the germ plasm, these RNAs are found enriched in polar granules which are RNA-protein particles specific for germ cells (Nakamura et al. 1996; Amikura et al. 2001). At egg deposition, the germ plasm containing these RNAs forms a crescent at the posterior pole of the embryo (stages 1-2) before it is incorporated into the developing germ cells (stages 3-4).

Table 1. RNAs localized to germ plasm

\begin{tabular}{lccc}
\hline RNA & Function & $\begin{array}{c}\text { Germ } \\
\text { plasm }^{\mathrm{a}}\end{array}$ & $\begin{array}{c}3^{\prime} \text { UTR } \\
\text { sufficiency }\end{array}$ \\
\hline nos & translational control & + & + \\
bruno & translational control & + & + \\
pgc & transcriptional silencing & + & + \\
gcl & germ cell formation & + & + \\
CG5292 & RNA binding $^{\mathrm{b}}$ & + & + \\
sra & $\mathrm{Ca}^{2+}$ signaling & + & + \\
CG18446 & zinc ion binding $^{\mathrm{b}}$ & + & + \\
CG2774 & endocytosis & + & + \\
cyclin B & cell cycle & + & + \\
orb & translational control & + & + \\
rapgap1 & GTPase & + & n.d. \\
\hline
\end{tabular}

Table lists the RNAs used in this study (column 1), their established or predicted $\left({ }^{\mathrm{b}}\right)$ function (column 2 ), localization to germ plasm (column 3), and sufficiency of $3^{\prime}$ UTR to localize reporter constructs to germ plasm (column 4).

n.d., not determined.

${ }^{a}$ Localization data from the Berkeley Drosophila Genome Project (Lecuyer et al. 2007; Tomancak et al. 2007).

${ }^{\mathrm{b}}$ Predicted function.
We created a reporter cassette to systematically test 3'UTRs of selected RNAs for their ability to recapitulate the endogenous RNA localization and translation pattern. The 3'UTRs of selected localized RNAs were added to this reporter cassette in which the maternally active nanos promoter and its 5'UTR was fused to green fluorescent protein (GFP), which was flanked by HA sequences at both the carboxyl and amino termini and transgenic lines (pnos::HA-GFP-HA-geneX3'UTR) were generated (Table 1; Fig. 1A). We found that the 3'UTRs of the selected RNAs were sufficient to localize the reporter RNA to the germ plasm (Rangan et al. 2008). We tested the translational state of these germ plasm RNAs and found that unlocalized RNA is not translated and RNA localized to the posterior pole is specifically translated (Rangan et al. 2008). We identified several patterns of translational regulation in the embryo (Fig. 2A). As described previously, nanos RNA is translated upon localization. We also observed a similar pattern for $o r b$ (class I; Fig. 2A); gcl RNA is translated as germ cell nuclei reach the germ plasm and germ cells begin to bud (class II; Fig. 2A); five RNAs (pgc, sra, CG5292, CG18446, and rapgap 1) are translated when germ cells are formed (class III; Fig. 2A); three RNAs (bruno, $C G 2774$, and $c y c l i n B$ ) are not translated in embryonic germ cells; only cyclinB is translated in germ cells at the end of embryogenesis (classes IV and V; Fig. 2A) (Rangan et al. 2008). These results suggest that localized RNAs are, in general, translationally regulated and that RNA localization does not necessarily act as a trigger for translational activation.

\section{MATERNALLY SUPPLIED GERM PLASM RNAS ARE DIFFERENTIALLY REGULATED DURING OOGENESIS}

To determine whether RNAs localized to the embryonic germ plasm are also translationally regulated during oogenesis and whether this regulation is mediated by their respective 3 'UTRs, we assayed the transgenic lines (pnos::HA-GFP-HA-geneX3'UTR) described above for expression during oogenesis. For each construct, we analyzed the pattern of GFP or HA-tag expression during all stages of oogenesis. Drosophila ovary development is divided into 14 stages. Drosophila egg chambers of different stages mature in one of 16 ovarioles in each ovary (see Fig. 1B). At the tip of the ovariole, germ-line stem cells regenerate and produce a differentiating daughter cell called the cystoblast. The cystoblast undergoes four synchronous incomplete cell divisions, giving rise to a 16cell interconnected cyst. Only one of the 16 cells of a cyst becomes the oocyte, whereas the others become nurse cells that are connected to the oocyte by ring canals that allow the passage of proteins and RNAs from the nurse cells into the oocyte. Somatic follicle cells surround the 16-cell cyst. During oogenesis, nurse cells and follicle cells endoreplicate and the oocyte grows in volume. At the end of oogenesis, the nurse cells dump their contents into the oocyte and degenerate.

We observed three principle patterns of RNA regulation during oogenesis (Fig. 2B; Table 2). RNAs in the first 


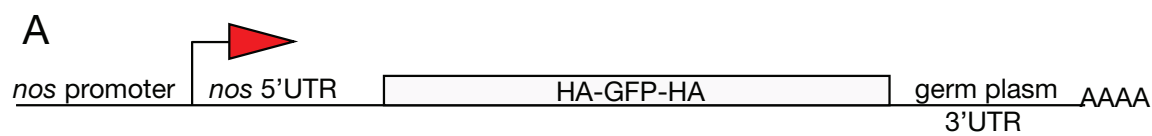

B
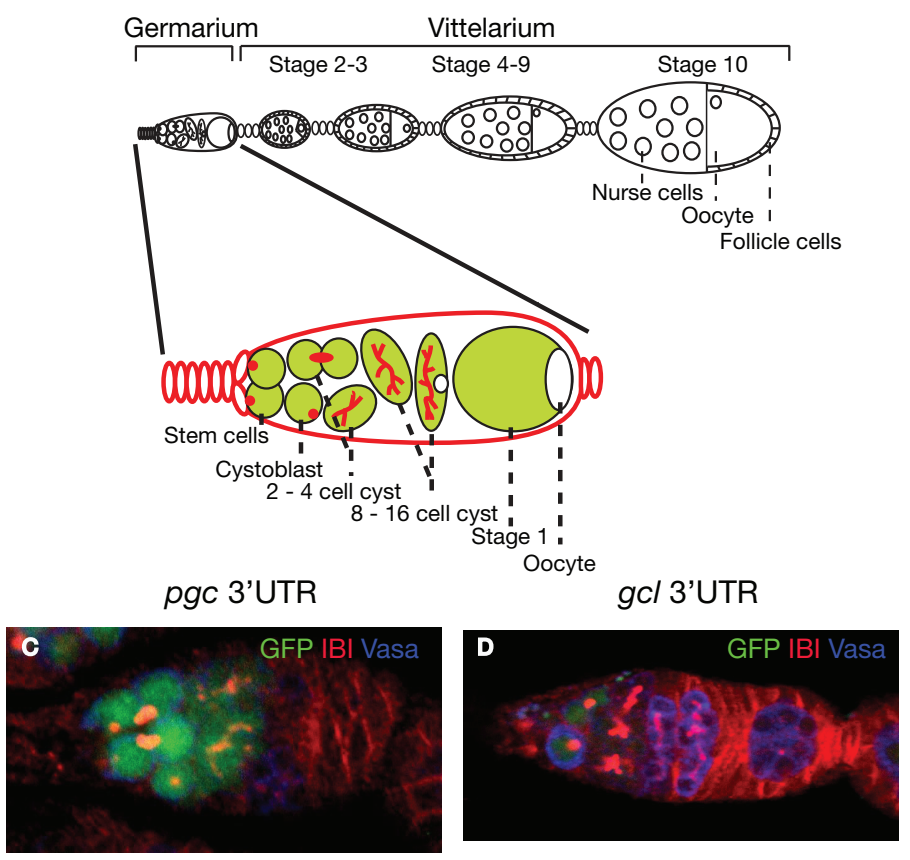

sra 3'UTR

CG5292 3'UTR
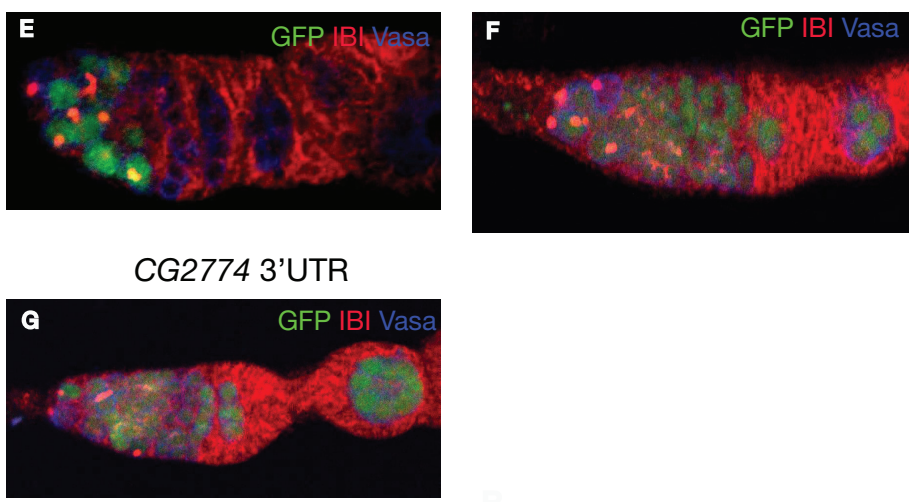

Figure 1. Germ plasm RNAs are regulated in the germarium by their 3'UTRs. (A) Reporter construct that was used to test various germ plasm 3'UTRs used in this study. (B) Summary of Drosophila oogenesis. Each ovary is comprised of 16-18 ovarioles (top). Each ovariole contains 2-3 stem cells in the germarium (below). $(C-G)$ Expression patterns of various transgenes under control of indicated 3'UTR monitored by GFP expression (green). Anti-Vasa (blue) marks the germ line. IB1 (red) marks spectrosome, fusome, and the somatic cell membranes. Reporter constructs fused to $\mathrm{pgc}, \mathrm{gcl}$, and $\mathrm{sra} 3^{\prime} \mathrm{UTR}$ show expression in anteriormost part of the germarium and are then silenced. Germaria are oriented with the niche containing the stem cells to the left.

class were expressed strongly in the early stages of oogenesis in the germarium. These included pgc, CG18446, gcl, and sra (Table 2; Fig. 1C-E). pgc and CG18446 expression was only observed in the germarium and we detected very little expression during later stages, whereas $\mathrm{gcl}$ and sra expression was detected throughout oogenesis (Table 2; Fig. 3A-C). The second pattern displayed by $C G 5292$ and $C G 2774$ showed more uniform expression throughout all stages of oogenesis (Table 2; Figs. 1F,G and 3D,E). The third pattern was exemplified by bruno and orb 3'UTRs and showed low expression in early germarial stages and up-regulation during later stages of oogenesis (Table 2). Indeed this pattern very closely resembled the pattern of expression of the endogenous Bruno and Orb proteins (Table 2) (Lantz et al. 1994; Webster et al. 1997). These results show that 3'UTRs also carry information about translational control during oogenesis. Most interestingly, RNAs sharing an expression pattern during oogenesis are not necessarily coregulated during embryogenesis. 
A. Embryo

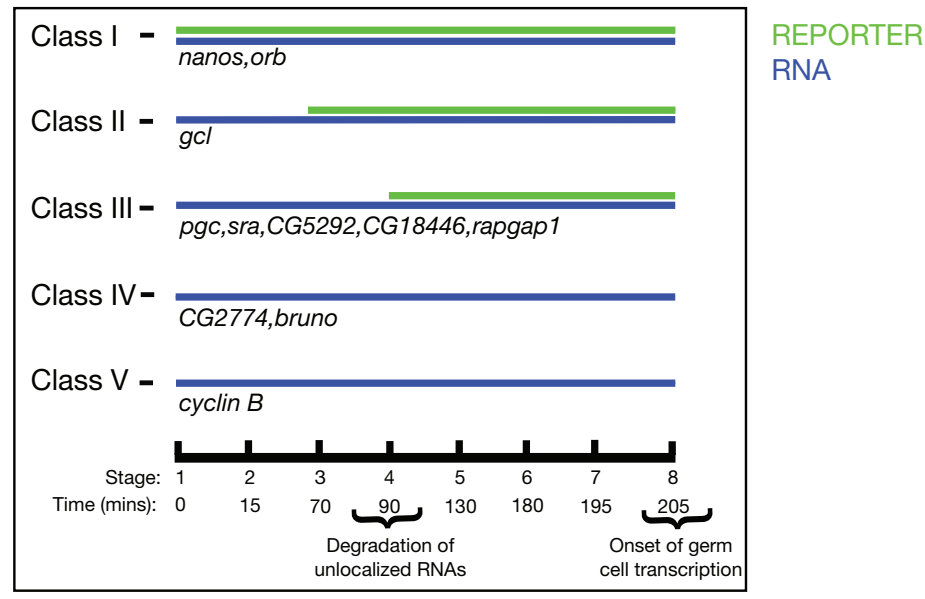

\section{B. Oogenesis}

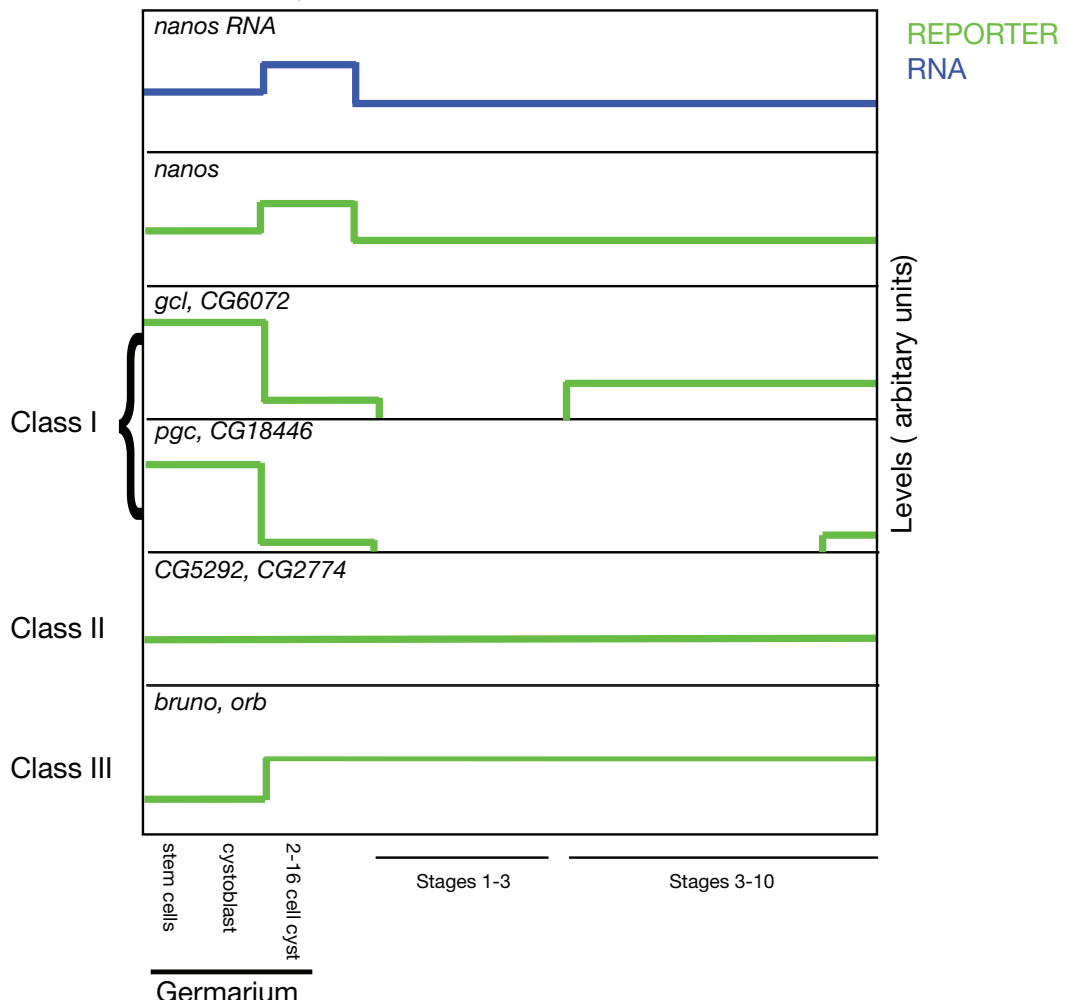

Figure 2. RNAs localized to germ plasm are spatially and temporally regulated during germ-line development. $(A)$ Germ plasm RNAs are classified into five classes according to the timing of onset of translation of the reporter or endogenous protein. The RNAs that belong to each of these classes are shown below the corresponding classes. (Green line) Expression of the reporter construct under control of the respective 3'UTRs; (blue line) endogenous localized RNA; (black line) time line of embryonic development after egg deposition. Class IV showed no expression of reporter construct in the germ line. Class V was tested for expression of endogenous protein and showed no protein expression in the germ line, but protein was expressed in the soma. (B) (Blue) Expression profile of the nanos promoter used for all of the reporter constructs; (green line) expression of the reporter construct under control of the respective 3'UTRs as indicated. The reporters carrying germ plasm RNA 3'UTRs have at least three classes of expression patterns, showing that despite carrying the same promoter and 5'UTR, the 3'UTRs dictate translation of these RNAs. The time line of oogenesis is indicated at the bottom of the panel. 
Table 2. Regulation of germ plasm RNA during oogenesis

\begin{tabular}{|c|c|c|c|c|c|c|c|c|c|}
\hline Promoter & $\begin{array}{l}\text { Protein } \\
\text { 3'UTR }\end{array}$ & $\begin{array}{l}\text { Stem } \\
\text { cells }\end{array}$ & $\begin{array}{l}\text { Cysto- } \\
\text { blast }\end{array}$ & $\begin{array}{l}\text { 4-cell } \\
\text { cyst }\end{array}$ & $\begin{array}{c}16 \text {-cell } \\
\text { cyst }\end{array}$ & $\begin{array}{c}\text { Stages } \\
2 \mathrm{a}-3\end{array}$ & $\begin{array}{c}\text { Stages } \\
3-10\end{array}$ & $\begin{array}{c}\text { Stage } \\
10\end{array}$ & Reference \\
\hline nanos & Gal4-tublin 3'UTR & $+1-$ & $+1-$ & + & + & + & + & + & $\begin{array}{c}\text { Swantek and Gergen } \\
(2004) ; \text { this study }\end{array}$ \\
\hline nanos & NosGFP-nos 3'UTR & + & + & ++ & ++ & + & + & + & Forrest and Gavis (2003) \\
\hline nanos & moeRFP-nos 3'UTR & + & + & ++ & ++ & + & + & + & this study \\
\hline nanos & NANOS & + & $+1-$ & ++ & ++ & + & + & + & $\begin{array}{l}\text { Wang and Lehmann } \\
\text { (1994) }\end{array}$ \\
\hline nanos & GFP-pgc 3'UTR & ++ & ++ & + & $+1-$ & - & - & $+1-$ & this study \\
\hline nanos & GFP-CG18446 3’UTR & ++ & ++ & + & $+1-$ & - & - & $+1-$ & this study \\
\hline nanos & GFP-gcl 3'UTR & ++ & ++ & $+/-$ & - & - & + & + & this study \\
\hline nanos & GFP-sra 3'UTR & ++ & ++ & $+1-$ & - & - & + & + & this study \\
\hline hsp 83 & lacZ-orb 3'UTR & - & - & - & + & + & + & + & Lantz and Schedl (1994) \\
\hline Orb & ORB & - & - & - & + & + & + & + & Lantz et al. (1994) \\
\hline nanos & GFP-bru 3'UTR & + & + & + & + & + & + & + & this study \\
\hline Bruno & BRUNO & - & - & - & + & + & + & + & Webster et al. (1997) \\
\hline nanos & GFP-CG5292 3'UTR & + & + & + & + & + & + & + & this study \\
\hline nanos & GFP-CG2774 3'UTR & + & + & + & + & + & + & + & this study \\
\hline
\end{tabular}

Table lists the promoters for the reporter constructs used in this study (column 1), reporters used in this study fused to the $3^{\prime} \mathrm{UTR}_{\mathrm{S}}$ as indicated (column 2), and expression in different stages of oogenesis as indicated (column 3-7). (Dark gray) Regions of highest reporter expression (++); (light gray) regions of intermediate reporter expression (+/-); (white) regions of no reporter expression (-). Expression of endogenous proteins is shown below the reporter constructs.
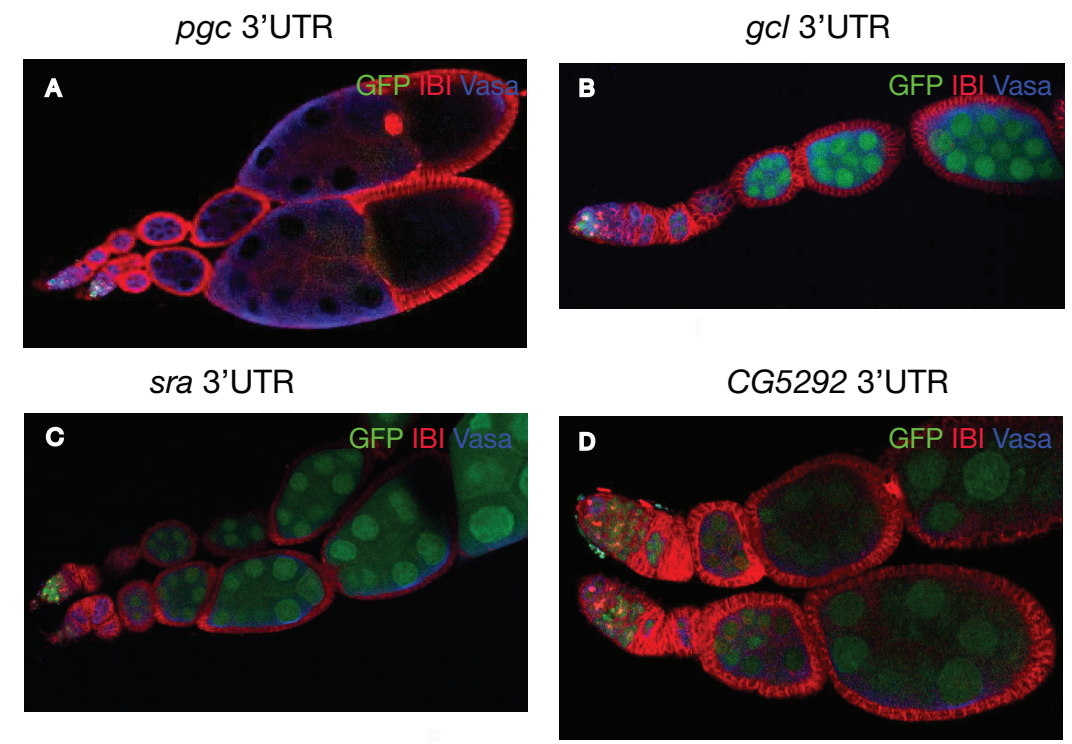

CG2774 3'UTR

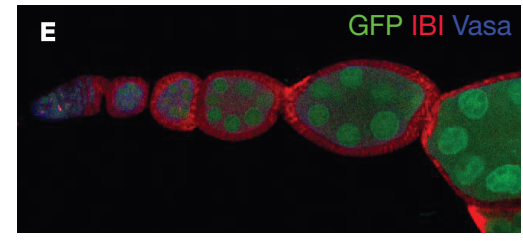

Figure 3. Germ plasm RNAs are regulated throughout oogenesis by their 3'UTRs. Expression patterns of various transgenes under control of the indicated 3'UTRs monitored by GFP expression (green). Anti-Vasa (blue) marks the germ line. IB1 (red) marks spectrosomes, fusomes, and the somatic cell membranes. Reporter fused to $p g c 3^{\prime} \mathrm{UTR}$ is completely repressed in later stages. Reporter fused to $\mathrm{gcl}$ and $\mathrm{sra} 3^{\prime} \mathrm{UTR}$ is repressed in early stages of vitellogenesis but is expressed in later stages. Reporter fused to CG5292 and CG2774 3'UTRs is uniformly expressed. Egg chambers are oriented with the earlier stages to the left. 


\section{TRANSCRIPTIONAL REGULATION OF NANOS IN THE GERMARIUM}

The pattern of Nanos protein during oogenesis has been well studied (Wang et al. 1994; Forbes and Lehmann 1998). Nanos protein is expressed at low level in stem cells and cystoblasts and is up-regulated in 2-16 cell cysts and then expressed at moderate levels in the nurse cells throughout oogenesis (Forbes and Lehmann 1998). None of the heterologous $3^{\prime} \mathrm{UTR}$ reporters exhibited this pattern. To distinguish between genuine regulation of translation or stability and the transcriptional aspects conveyed by the nanos promoter, we analyzed the expression pattern generated by a transgene that contained the nanos promoter, the GAL4 coding sequence, and an "inert" tubulin 3'UTR (pnos::GAL4-tub3'UTR), which is unlikely to confer specific translational regulatory function. Expression of this construct was analyzed in females carrying the pnos::GAL4-tub3'UTR and UAS-GFP-tubulin3'UTR. GFP was expressed weakly in stem cells and dividing cystoblasts and more strongly in 16 cell cysts. Strongest expression was observed in oocytes from stages 2-3 onward (Table 2; Fig. 4) (Wang et al. 1994). This pattern was not observed with any of the 3'UTRs used, suggesting that the respective $3^{\prime}$ UTRs recapitulate diverse patterns of translational control during oogenesis, largely independent of transcriptional regulation (Fig. 4C). These results suggest that during oogenesis, nos is regulated at the transcriptional and translational levels.

\section{MATERIALS AND METHODS}

The following stocks were used in this study: $w^{118}$, nos::Gal4-VP16-nos3'UTR, nos::Gal4-VP16-tub3'UTR, UAS-GFP-k103'UTR, and UAS-moeRFP-nos 3'UTR. Fixation and immunostaining of ovaries were carried out as previously described (Forbes and Lehmann 1998). Rabbit anti-Vasa antibody was used at a dilution of 1:5000. IB1 monoclonal supernatant was used at 1:25 (Developmental Studies Hybridoma Bank). Secondary antibodies (Invitrogen) were used at 1:500. The reporters were monitored by direct fluorescence microscopy for GFP and RFP, and LacZ was monitored by antibody staining. Immunostainings was visualized using a Zeiss LSM 510 Meta confocal microscope using 10x, 20x, and oil-immersed 40x lenses.

\section{CONCLUSIONS}

Translational regulation is a widespread phenomenon and has been observed in particular for RNAs, such as oskar, nanos, gurken, and orb, during oogenesis (Johnstone and Lasko 2001). These RNAs are specifically transported into the oocyte and are localized to a particular region of the developing egg. In these cases, translational regulation is closely linked to localization, because RNAs are translationally repressed during transport and are translated upon localization. Our analysis of 3'UTR reporter constructs revealed that a significant number of maternal RNAs, that become localized to the posterior pole late during oogenesis and are part of the germ plasm in the early embryo, are also regulated at the translational level during the early stages of oogenesis. We observe translational regulatory patterns during oogenesis that are apparently independent of a particular localization pattern and the timing of translation during embryogenesis.

Posttranscriptional regulation of RNA is a widespread phenomenon in germ cells but also in other stem cells (Chen and Daley 2008; Kohlmaier and Edgar 2008). Our systematic study emphasizes the regulatory role that 3'UTRs have in this regulation. Trans-acting factors such

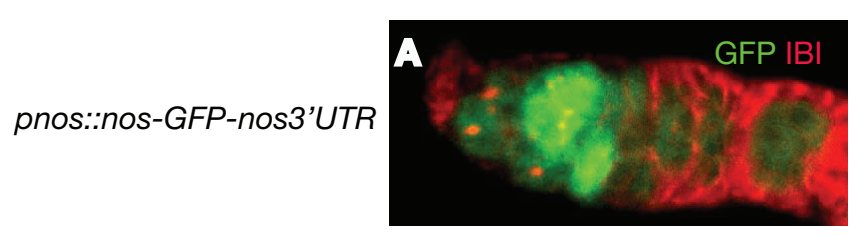

pnos::GAL4-tub3'UTR; UASp-GFP-k10 3'UTR

pnos::GFP-pgc 3'UTR; pnos::RFP-nos 3'UTR
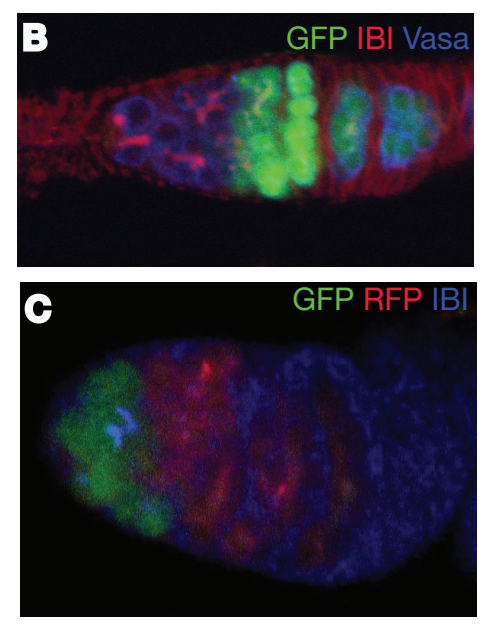

Figure 4. Nanos is transcriptionally regulated in the germarium. (A) Nanos-GFP fusion protein (green) expressed under the control of its endogenous promoter and $5^{\prime}$ and $3^{\prime}$ UTR shows an up-regulation of protein expression in the 4-16-cell cyst. IB1 (red) marks spectrosomes, fusomes, and the somatic cell membranes. (B) GFP (green) expressed under control of the nanos promoter and tubulin $3^{\prime} \mathrm{UTR}$ also shows an up-regulation of expression in the 16-cell cyst and a down-regulation in later stages, demonstrating the role of the promoter and on nos regulation. Anti-Vasa (blue) marks the germ line. IB1 (red) marks spectrosomes, fusomes, and the somatic cell membranes. (C) Red fluorescent protein (RFP) under the control of the nanos promoter and nanos 3'UTR also has an up-regulation in the 16-cell cyst, showing that the upregulation is not due to protein stability. GFP (green) under the control of the nanos promoter and pgc $3^{\prime} \mathrm{UTR}$ shows expression in the germarium and down-regulation in 16-cell cyst, showing the effect of the pgc $3^{\prime}$ UTR. Germaria are oriented with the niche containing the stem cells to the left. 
as specific RNA-binding proteins or microRNAs (miRNAs) have been shown to regulate RNA translational repression, often by interfering with the ability of the poly(A) tail to stimulate translational initiation (Besse and Ephrussi 2008; Kohlmaier and Edgar 2008). Less is known about the mechanisms that activate translationally repressed RNAs. It has been suggested that either competition among binding factors for the RNA or signaling events such as phosphorylation inactivate repressors or target components of the translational activation machinery (Besse and Ephrussi 2008). How this regulatory information is encoded within $3^{\prime}$ UTRs and is integrated over space and time remains largely unclear. By comparing translation patterns of the same RNAs during embryogenesis and oogenesis, we found that RNAs coregulated at one stage are not necessarily coregulated at another stage (Table 3). Thus, different trans-acting factors or combinations of factors must control the response of the 3'UTR. Our results suggest that the repertoire of trans-acting factors may itself be regulated by translation. For example, bruno, which encodes a translational repressor, and orb, which encodes the Drosophila CPEB homolog that regulates poly(A) elongation, are coregulated during oogenesis, but bruno RNA is completely silenced during embryogenesis, whereas orb is translated in the germ plasm (Fig. 2) (Kim-Ha et al. 1995; Webster et al. 1997; Chang et al. 1999; Castagnetti et al. 2000). Further systematic analysis of RNA localization and translation within its developmental context should reveal a code for 3'UTR-mediated RNA regulation that promises to be as complex and multileveled as the much better known transcriptional control mechanisms. Importantly, because some germ cells share the ability to self-propagate with other stem cells, we expect that principles discovered by the analysis of RNA regulation in germ cells will also provide insight into the regulation and maintenance of other stem cell populations (Surani et al. 2007; Chen and Daley 2008; Kohlmaier and Edgar 2008; Sampath et al. 2008).

Table 3. Regulation of germ plasm RNAs in the ovary does not parallel regulation in the embryo

\begin{tabular}{|c|c|c|c|}
\hline \multicolumn{2}{|c|}{$\begin{array}{c}\text { Classes of similarly } \\
\text { regulated RNAs in } \\
\text { oogenesis } \\
\text { (stem cells-stage 10) }\end{array}$} & \multicolumn{2}{|c|}{$\begin{array}{l}\text { Classes of similarly } \\
\text { regulated RNAs in } \\
\text { embryogenesis } \\
\text { (stages 1-5) }\end{array}$} \\
\hline & nanos & Class 1 & $\begin{array}{c}\text { nanos } \\
\text { orb }\end{array}$ \\
\hline Class I & $\begin{array}{c}p g c \\
\text { CG18846 } \\
\text { gcl } \\
\text { sra }\end{array}$ & Class 2 & gcl \\
\hline Class II & $\begin{array}{l}\text { CG2774 } \\
\text { CG5292 }\end{array}$ & Class 3 & $\begin{array}{c}p g c \\
\text { CG18846 } \\
\text { CG5292 } \\
\text { sra } \\
\text { rapgap1 }\end{array}$ \\
\hline \multirow[t]{2}{*}{ Class III } & $\begin{array}{l}\text { bru } \\
\text { orb }\end{array}$ & Class 4 & $\begin{array}{c}\text { bru } \\
\text { CG2774 }\end{array}$ \\
\hline & & Class 5 & cyclin $B$ \\
\hline
\end{tabular}

\section{ACKNOWLEDGMENTS}

We thank Paul Schedl and Iswar Hariharan for flies and antibodies. We also thank Alexey Arkov for the gift of the plasmid containing the nanos promoter with the nanos 5'UTR linked to GFP. P.R. is an HHMI Research Associate. R.L. is an HHMI investigator and a member of the Kimmel Center for Stem Cell Biology at NYULMC.

\section{REFERENCES}

Amikura, R., Kashikawa, M., Nakamura, A., and Kobayashi, S. 2001. Presence of mitochondria-type ribosomes outside mitochondria in germ plasm of Drosophila embryos. Proc. Natl. Acad. Sci. 98: 9133-9138.

Ancelin, K., Lange, U.C., Hajkova, P., Schneider, R., Bannister, A.J., Kouzarides, T., and Surani, M.A. 2006. Blimp1 associates with Prmt5 and directs histone arginine methylation in mouse germ cells. Nat. Cell Biol. 8: 623-630.

Besse, F. and Ephrussi, A. 2008. Translational control of localized mRNAs: Restricting protein synthesis in space and time. Nat. Rev. Mol. Cell Biol. 9: 971-980.

Castagnetti, S., Hentze, M.W., Ephrussi, A., and Gebauer, F. 2000. Control of oskar mRNA translation by Bruno in a novel cell-free system from Drosophila ovaries. Development 127: 1063-1068.

Chang, J.S., Tan, L., and Schedl, P. 1999. The Drosophila CPEB homolog, orb, is required for oskar protein expression in oocytes. Dev. Biol. 215: 91-106.

Chen, L. and Daley, G.Q. 2008. Molecular basis of pluripotency. Hum. Mol. Genet. 17: R23-R27.

Cinalli, R.M., Rangan, P., and Lehmann, R. 2008. Germ cells are forever. Cell 132: 559-562.

Forbes, A. and Lehmann, R. 1998. Nanos and Pumilio have critical roles in the development and function of Drosophila germline stem cells. Development 125: 679-690.

Forrest, K.M. and Gavis, E.R. 2003. Live imaging of endogenous RNA reveals a diffusion and entrapment mechanism for nanos mRNA localization in Drosophila. Curr. Biol. 13: 1159-1168.

Gilboa, L. and Lehmann, R. 2004. Repression of primordial germ cell differentiation parallels germ line stem cell maintenance. Curr. Biol. 14: 981-986.

Hanyu-Nakamura, K., Sonobe-Nojima, H., Tanigawa, A., Lasko, P., and Nakamura, A. 2008. Drosophila Pgc protein inhibits P-TEFb recruitment to chromatin in primordial germ cells. Nature 451: 730-733.

Hayashi, Y., Hayashi, M., and Kobayashi, S. 2004. Nanos suppresses somatic cell fate in Drosophila germ line. Proc. Natl. Acad. Sci. 101: 10338-10342.

Hayashi, K., de Sousa Lopes, S.M., and Surani, M.A. 2007. Germ cell specification in mice. Science 316: 394-396.

Johnstone, O. and Lasko, P. 2001. Translational regulation and RNA localization in Drosophila oocytes and embryos. Annu. Rev. Genet. 35: 365-406.

Jongens, T.A., Hay, B., Jan, L.Y., and Jan, Y.N. 1992. The germ cell-less gene product: A posteriorly localized component necessary for germ cell development in Drosophila. Cell 70: 569-584.

Kim-Ha, J., Kerr, K., and Macdonald, P.M. 1995. Translational regulation of oskar mRNA by Bruno, an ovarian RNA-binding protein, is essential. Cell 81: 403-412.

Kohlmaier, A. and Edgar, B.A. 2008. Proliferative control in Drosophila stem cells. Curr. Opin. Cell Biol. 20: 699-706.

Lantz, V. and Schedl, P. 1994. Multiple cis-acting targeting sequences are required for orb mRNA localization during Drosophila oogenesis. Mol. Cell. Biol. 14: 2235-2242.

Lantz, V., Chang, J.S., Horabin, J.I., Bopp, D., and Schedl, P. 1994. The Drosophila orb RNA-binding protein is required for the formation of the egg chamber and establishment of polarity. Genes Dev. 8: 598-613.

Lecuyer, E., Yoshida, H., Parthasarathy, N., Alm, C., Babak, T., 
Cerovina, T., Hughes, T.R., Tomancak, P., and Krause, H.M. 2007. Global analysis of mRNA localization reveals a prominent role in organizing cellular architecture and function. Cell 131: 174-187.

Martinho, R.G., Kunwar, P.S., Casanova, J., and Lehmann, R. 2004. A noncoding RNA is required for the repression of RNApolII-dependent transcription in primordial germ cells. Curr. Biol. 14: 159-165.

Nakamura, A. and Seydoux, G. 2008. Less is more: Specification of the germline by transcriptional repression. Development 135: 3817-3827.

Nakamura, A., Amikura, R., Mukai, M., Kobayashi, S., and Lasko, P.F. 1996. Requirement for a noncoding RNA in Drosophila polar granules for germ cell establishment. Science 274: 2075-2079.

Ohinata, Y., Payer, B., O'Carroll, D., Ancelin, K., Ono, Y., Sano, M., Barton, S.C., Obukhanych, T., Nussenzweig, M., Tarakhovsky, A., Saitou, M., and Surani, M.A. 2005. Blimp1 is a critical determinant of the germ cell lineage in mice. Nature 436: 207-213.

Rangan, P., DeGennaro, M., Jaime-Bustamante, K., Coux, R., Martinho, R., and Lehmann, R. 2008. Temporal and spatial control of germ plasm RNAs. Curr. Biol. 19: 72-77.

Sampath, P., Pritchard, D.K., Pabon, L., Reinecke, H., Schwartz, S.M., Morris, D.R., and Murry, C.E. 2008. A hierarchical network controls protein translation during murine embryonic stem cell self-renewal and differentiation. Cell Stem Cell 2: $448-460$.

Sato, K., Hayashi, Y., Ninomiya, Y., Shigenobu, S., Arita, K., Mukai, M., and Kobayashi, S. 2007. Maternal Nanos represses $\mathrm{hid} / \mathrm{skl}$-dependent apoptosis to maintain the germ line in Drosophila embryos. Proc. Natl. Acad. Sci. 104: $7455-7460$.

Seydoux, G. and Braun, R.E. 2006. Pathway to totipotency: Lessons from germ cells. Cell 127: 891-904.
Seydoux, G., Mello, C.C., Pettitt, J., Wood, W.B., Priess, J.R., and Fire, A. 1996. Repression of gene expression in the embryonic germ lineage of C. elegans. Nature 382: 713-716.

Strome, S. and Lehmann, R. 2007. Germ versus soma decisions: Lessons from flies and worms. Science 316: 392-393.

Subramaniam, K. and Seydoux, G. 1999. nos-1 and nos-2, two genes related to Drosophila nanos, regulate primordial germ cell development and survival in Caenorhabditis elegans. Development 126: 4861-4871.

Surani, M.A., Hayashi, K., and Hajkova, P. 2007. Genetic and epigenetic regulators of pluripotency. Cell 128: 747-762.

Swantek, D. and Gergen, J.P. 2004. Ftz modulates Runt-dependent activation and repression of segment-polarity gene transcription. Development 131: 2281-2290.

Tomancak, P., Berman, B.P., Beaton, A., Weiszmann, R., Kwan, E., Hartenstein, V., Celniker, S.E., and Rubin, G.M. 2007. Global analysis of patterns of gene expression during Drosophila embryogenesis. Genome Biol. 8: R145.

Vincent, S.D., Dunn, N.R., Sciammas, R., Shapiro-Shalef, M., Davis, M.M., Calame, K., Bikoff, E.K., and Robertson, E.J. 2005. The zinc finger transcriptional repressor Blimp1/Prdm1 is dispensable for early axis formation but is required for specification of primordial germ cells in the mouse. Development 132: $1315-1325$.

Wang, C. and Lehmann, R. 1991. Nanos is the localized posterior determinant in Drosophila. Cell 66: 637-647.

Wang, Z. and Lin, H. 2004. Nanos maintains germline stem cell self-renewal by preventing differentiation. Science 303: 2016-2019.

Wang, C., Dickinson, L.K., and Lehmann, R. 1994. Genetics of nanos localization in Drosophila. Dev. Dyn. 199: 103-115.

Webster, P.J., Liang, L., Berg, C.A., Lasko, P., and Macdonald, P.M. 1997. Translational repressor bruno plays multiple roles in development and is widely conserved. Genes Dev. 11: 2510-2521. 


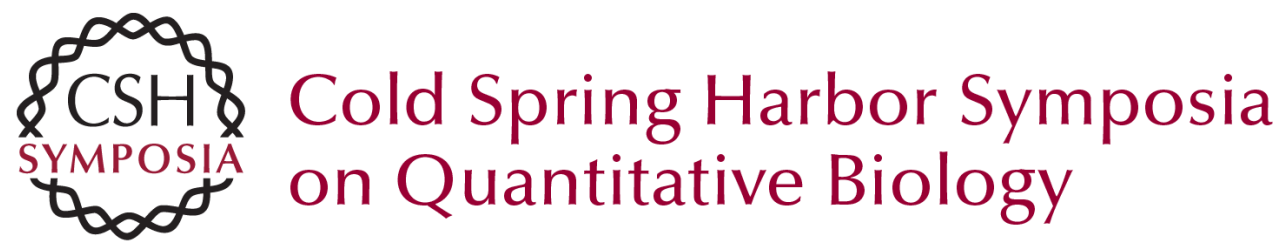

\section{Regulating Gene Expression in the Drosophila Germ Line}

P. Rangan, M. DeGennaro and R. Lehmann

Cold Spring Harb Symp Quant Biol 2008 73: 1-8 originally published online March 6, 2009 Access the most recent version at doi:10.1101/sqb.2008.73.057

References This article cites 39 articles, 16 of which can be accessed free at: http://symposium.cshlp.org/content/73/1.full.html\#ref-list-1

License

Email Alerting Receive free email alerts when new articles cite this article - sign up in the box at the Service top right corner of the article or click here.

To subscribe to Cold Spring Harbor Symposia on Quantitative Biology go to:

http://symposium.cshlp.org/subscriptions 